\title{
Brasil, estudos pós-coloniais e contracorrentes análogas: entrevista com Ella Shohat e Robert Stam
}

\author{
Emanuelle Santos \\ Universidade de Utrecht \\ Patricia Schor \\ Universidade de Utrecht
}

Foi com prazer que entrevistamos a professora Ella Shohat e o professor Robert Stam, da Universidade de Nova lorque, durante sua visita à Holanda para participar de dois eventos promovidos pelo Postcolonial Initiative da Universidade de Utrecht. Nesta entrevista Ella Shohat e Robert Stam tocam em assuntos de importância crítica para a reflexão sobre os temas desenvolvidos no número 4 do Portuguese Cultural Studies. ${ }^{1}$ 
${ }^{2}$ STAM E SHOHAT, 2012 a.

${ }^{3}$ VELOSO, 1997a.

Emanuelle Santos (ES)/Patricia Schor (PS): Um ponto de partida no campo pós-colonial em português tem sido "queremos cair fora" ou "queremos oferecer algo diferente" da teoria anglo-pós-colonial. O que vocês pensam sobre isso?

Shohat: Gostaríamos de discutir essa terminologia, porque a consideramos problemática. Primeiramente, achamos que os estudos lusófonos e brasileiros deveriam oferecer algo diferente da teoria pós-colonial anglófona! Nossa crítica sobre certos aspectos dos Estudos Pós-Coloniais é parte de nosso novo livro, ${ }^{2}$ e acho que é importante, porque acreditamos que um pouco da rejeição eventual dos Estudos Pós-Coloniais na França e no Brasil tem a ver com a projeção dos Estudos Pós-Coloniais como os "anglo-saxões" em oposição aos "latinos". De forma que vários projetos intelectuais que são de fato bastante transnacionais, tais como a Teoria Pós-Colonial, os Estudos Críticos de Raça, os Estudos Multiculturais e até mesmo os Estudos Feministas, ficaram presos nessa velha dicotomia regional - no final, um tipo de construto, e mesmo um fantasma - que vê ideias como etnicamente marcadas como "latinas" ou "anglo-saxãs".

Argumentamos no livro que os dois termos são impróprios, que a América "Latina" também é indígena, africana e asiática, da mesma maneira que a América supostamente "anglo-saxã" é também indígena, africana e asiática. $O$ projeto de nosso livro é ir além dos estados-nação etnicamente definidos, para uma visão relacional, transnacional das nações como palimpsésticas e múltiplas.

Stam: Para nós, todas as Américas, apesar das hegemonias imperiais, também têm muito em comum, tanto de formas negativas (conquista, despossessão indígena, escravatura transatlântica) quanto positivas (sincretismo artístico, pluralismo social) e assim por diante. No seu livro de memórias, Verdade Tropical, ${ }^{3}$ Caetano Veloso diz que, assim como o Brasil, os EUA são fatalmente mestiços - inevitavelmente mestiços - mas escolhem, por racismo, não o admitir. O ódio virulento da direita contra Obama, nesse sentido, revela um medo desse caráter mestiço da nação americana.

Shohat: Não é coincidência que a relação entre as diásporas afro-americanas e outras diásporas africanas nas Américas tem sido bastante forte. Tais colaborações não fazem sentido dentro de uma dicotomia "anglo-saxão" versus "latino". Propomos, no livro, que a palavra "anglo-saxão" - que designa duas tribos germânicas extintas que se mudaram para a Inglaterra há mais de mil anos - seja trocada pela palavra "anglo-saxonista" como sinônimo de racismo. Quase todos os escritores que gabam os valores "anglo-saxões" - Mitt Romney é o último a alardear essa herança - foram supremacistas brancos e racistas extermina- 
cionistas. Nós vemos a dicotomia latina versus a anglófona como um sintoma daquilo que chamamos o "narcisismo intercolonial". Portanto, precisamos de outro vocabulário e outra gramática.

Stam: É sobre duas versões do eurocentrismo, a versão do norte da Europa e a versão do sul da Europa sobre a superioridade europeia, o anglo-saxonismo e uma latinité que se originou, como mostram [Walter] Mignolo e outros, em intervenções francesas no México.

Embora a versão do sul da Europa tenha sido posteriormente subalternizada, no início os britânicos e os norteamericanos, na verdade, invejavam Portugal e Espanha por seus impérios, porque ficaram ricos graças à riqueza mineral da América do Sul, que a América do Norte não tinha.

É interessante a história de Hipólito da Costa, um diplomata português/brasileiro que foi a Washington na época de revolução americana e relatou que "o povo é tão pobre, e eles se casam com indígenas" - todas as características que são, em geral, associadas ao Brasil.

Claro que muito da resistência a essas correntes acadêmicas provém do ressentimento legítimo sobre o enorme poder da academia anglófona. Esse poder, e o privilégio dado à língua inglesa, têm suas raízes históricas no poder do Império Britânico (Pax Britanica) e dos EUA como herdeiros daquele império (Pax Americana). Como Mário de Andrade há muito tempo observou, o poder cultural de uma nação está, de certa forma, relacionado ao poder de seus exércitos e sua moeda.

Um dos pontos de nosso novo livro é questionar a divisão internacional do trabalho intelectual, o sistema que exalta os pensadores do Norte Global em detrimento dos pensadores do Sul Global, que considera Henry James "naturalmente" mais importante que Machado de Assis, Fredric Jameson mais importante que Roberto Schwarz, Jacques Rancière mais importante que Marilena Chaui ou Ismail Xavier, e Sinatra mais importante que Jobim. Outro exemplo dessa hierarquia é que conceitos como "hibridez" são atribuídos ao professor Homi Bhabha, de Harvard, quando os intelectuais latino-americanos já falavam sobre a hibridez há no mínimo meio século (sobre o que era a "antropofagia"?). De qualquer maneira, estamos menos interessados em gurus e maîtres à penser do que nos circuitos transnacionais do discurso. Por isso sugerimos que os teóricos pós-coloniais olhem além dos impérios britânico e francês, olhem para a América Latina, olhem para a AfroAmérica, para os pensadores francófonos, para os povos indígenas na Europa, afro-americanos na França, todos os intelectuais diaspóricos entrecruzados.

Shohat: Os intelectuais latino-americanos têm sido vanguarda na mestiçagem, métissage, Antropofagia. Enquanto certamente 
${ }^{4}$ SHOHAT, 1992.

${ }^{5}$ SAID, 1978.

nos consideramos parte da teoria pós-colonial, temos também criticado alguns de seus aspectos, por exemplo, a celebração a-histórica, a-crítica do discurso da hibridez. Perguntamos: "Quais são as genealogias desses discursos?" Preferimos enfatizar a questão de "analogias relacionadas" entre e através das fronteiras nacionais. Então, para nós, a análise transfronteiriça torna-se realmente crucial. Não pode ser reduzida a formações de estado-nação.

Stam: Ao contrário, discutimos em nosso novo livro que o estadonação pode ser visto como altamente problemático se adotarmos uma perspectiva indígena, uma vez que as nações indígenas não eram Estados. Elas foram vitimizadas pelos estados-nação europeizados, e eram algumas vezes filosoficamente contrárias, como observa Pierre Clastres, ao próprio conceito de estados-nação e sociedades baseados em coerção. Era isso que os modernistas brasileiros elogiavam nelas, não tinham polícia, nem exército, nem puritanismo.

Shohat: Também temos uma crítica à teoria pós-colonial, voltando a meu antigo ensaio, ${ }^{4}$ que demanda que se coloque a questão “Quando começa o pós-colonial?", a partir de uma perspectiva indígena. Os pensadores indígenas frequentemente veem sua situação como colonial, e não pós-colonial; ou como ambas as situações ao mesmo tempo. Enquanto uma determinada teoria pós-colonial celebra o cosmopolitismo, o discurso indígena frequentemente valoriza uma existência enraizada, em vez de cosmopolita. Enquanto os Estudos Culturais e Pós-Coloniais deleitam-se nas "fronteiras difusas", as comunidades indígenas amiúde buscam afirmar as fronteiras demarcando a terra, como vemos na Amazônia, contra invasores de terras, mineiros, estados-nação e corporações transnacionais.

Stam: Enquanto o pós-estruturalismo, que ajudou a dar forma ao pós-colonialismo, enfatiza a invenção das nações e "desnaturaliza o natural," os pensadores indígenas têm insistido no amor por uma terra considerada "sagrada", outra palavra dificilmente valorizada nos discursos do pós. Enquanto a teoria pós-colonial, numa vertente derridiana, milita contra o pensamento "originário"..., grupos nativos ameaçados querem recuperar uma cultura original parcialmente destruída pela conquista e pelo colonialismo. O que Eduardo Viveiros de Castro chama de "multinaturalismo" indígena desafia não apenas o antinaturalismo retórico dos "pós", mas também o que se poderia chamar de orientalismo primordial, aquele que separou a natureza da cultura, os animais dos seres humanos.

Shohat: Enquanto a obra Orientalism, de Edward Said, ${ }^{5}$ é geralmente considerada o marco inicial dos Estudos Pós-Coloniais 
${ }^{\circ}$ SHOHAT E STAM, 1994.

${ }^{7}$ ROCHA, 1967.

${ }^{8}$ BUARQUE E GIL, 1978. e tende a enfatizar os grandes impérios europeus do século XIX, e em menor medida o neo-império americano do século $X X$, preferimos evidenciar o imperialismo americano, mas também recuar ao ano 1492; por isso nosso livro anterior, Unthinking Eurocentrism, ${ }^{6}$ tem um capítulo inteiro sobre 1492. Já em Unthinking estávamos argumentando pela atenção ao vínculo entre os vários 1492, o da Inquisição, da expulsão dos mouros, da "descoberta", isto é, a conquista das Américas, e o início do comércio transatlântico de escravos, primeiramente de indígenas, depois de africanos. Os discursos sobre os judeus e muçulmanos - tais como a limpieza de sangre, que foi uma parte do discurso da Reconquista - na verdade viajaram para as Américas, onde foram postos em ação, já com Colombo, sobre os povos indígenas, em que o discurso antissemita do "libelo de sangue" foi transformado em discurso anticanibalista. Assim como os judeus e os muçulmanos eram demonizados na Europa, nas Américas o demonizado foi o Exu africano, bem como Tupã, a figura dos indígenas Tupi.

Shohat: A questão é que não podemos mais tomar isoladamente todos os temas do antissemitismo, islamofobia, racismo contra os negros, os massacres do povo indígena. Convencionalmente, acredita-se que a Inquisição contra os judeus levou ao Holocausto. Mas a Inquisição e a expulsão dos mouros, a conquista, também levaram à repressão das religiões indígenas e africanas.

Stam: Uma sequência maravilhosa em Terra em Transe, ${ }^{7}$ de Glauber Rocha, dramatiza o que Ella acabou de falar. A cena satiricamente reproduz a Primeira Missa de Cabral, com 0 personagem Porfirio Diaz como um golpista de direita. Cabral/ Diaz levanta o cálice, nós escutamos uma música de candomblé. Isto é muito profundo e sugestivo. Num retorno dos reprimidos, Rocha sobrepõe uma imagem da missa católica à música religiosa africana. Todos conhecemos a Inquisição espanhola, mas frequentemente nos esquecemos de que a conquista e 0 colonialismo europeu também levaram consigo um tipo de Inquisição contra as religiões indígenas e africanas. Também é interessante que o famoso esqueleto de "Luzia", descoberto no Brasil, foi descrito como tendo "características negroides". Glauber Rocha intuiu tudo isso. Colocando a música de candomblé enquanto Cabral/Diaz está levantando o cálice - nos recordamos de Afaste de mim este cálice, de Chico Buarque,$-{ }^{8}$ Glauber Rocha evoca todas essas contradições históricas/culturais. Podemos chamar isso de "transe brechtianismo". Ele usa a música de transe de possessão do candomblé para ir além de Bertold Brecht. Não é somente classe contra classe, mas cultura contra cultura. É a África, Europa, indígenas, tudo ao mesmo tempo. 
Uma das coisas que enfatizamos no livro é a imensa contribuição estética dos artistas latino-americanos, com sua invenção inesgotável: a Antropofagia, o Realismo Mágico, a Estética da Fome, a Tropicália, o manifesto afro-brasileiro Dogma Feijoada. Muitas das estéticas alternativas da América Latina estão baseadas em inversões anticoloniais. A Tropicália virou de cabeça para baixo a hostilidade em relação ao Trópico como "primitivo". A Antropofagia valorizou o canibal rebelde. O Realismo Mágico exaltou a mágica sobre a ciência ocidental. Nós achamos que a teoria pós-colonial poderia aprender com esse tipo de audácia e esse profundo repensar dos valores culturais.

Shohat: Porque eu acho que o que nos poderia preocupar é precisamente qualquer tipo de narrativa metadifusionista que vê o estudo pós-colonial como exclusivamente anglo-saxão, ou mesmo uma coisa anglófona que viaja para, digamos, o Brasil. Apenas veja por outra perspectiva, não é que não haja nada que o pós-colonial possa nos ensinar como método de leitura, como método de análise, mas nós deveríamos vê-lo como um discurso potencialmente policêntrico e aberto, a ser definido por múltiplos lugares e perspectivas. Nosso argumentochave sobre as multidirecionalidades das ideias é que o projeto pós-colonial e projetos similares emergem de muitos, muitos contextos. Há muitos predecessores ao lado da conhecida tríade pós-colonial Edward Said, Homi Bhabha e Gayatri Spivak. Reconhecemos sua importância, mas temos que nos lembrar de figuras como Frantz Fanon, Aimé Césaire.

Em nosso livro, falamos sobre a "mudança sísmica" que procurou descolonizar a cultura institucional e acadêmica. A Segunda Guerra Mundial, o nazismo, fascismo, Holocausto, descolonização, movimentos das minorias, tudo isso detonou uma crise na fé do Ocidente nas promessas de modernidade e progresso. Tudo convergiu para que o Ocidente duvidasse de si mesmo. A autoimagem do Ocidente e do mundo branco estava sendo questionada. Como resultado, você encontra desafios radicais dentro das disciplinas acadêmicas: Teoria da Dependência na Economia, onde os pensadores latinoamericanos tiveram um papel crucial; Teoria Terceiro-Mundista e posteriormente Pós-Colonial na Literatura; Antropologia Compartilhada e Dialógica; Teoria Crítica da Raça no Direito e nas Ciências Sociais, e assim por diante. Nós tendemos a nos esquecer dos precursores, como a escrita do cubano Roberto Fernández Retamar no início dos anos 1970.

Não minimiza a imensa contribuição de Said mostrar que, mesmo antes de seu Orientalism, Anouar Abdel-Malek, um egípcio marxista, no início dos anos 1960, escreveu uma crítica ao orientalismo, muito fanoniana em sua voz, que foi publicada

${ }^{9}$ ABDEL-MALEK, 1963. em francês. ${ }^{9} \mathrm{E}$ temos Abdul Latif Tibawi, outro escritor que falou de maneira critica sobre o orientalismo. Antes do surgimento 
${ }^{10}$ FANON, 1967[1952].

11 MCCLINTOCK, 1992.

12 HALL, 1996.

${ }^{13}$ FANON, 1965. dos Estudos Pós-Coloniais como termo ou rubrica em meados para final dos anos 1980, esse tipo de pensamento era chamado de Estudos Anticoloniais ou Estudos do Terceiro Mundo.

Stam: O que o pós-colonialismo trouxe foi a influência do pósestruturalismo, por isso a influência de Foucault (ao lado de Vico e Fanon) sobre Said, Derrida sobre Spivak, Lacan sobre Bhabha. O periódico do qual eu fazia parte, Jump Cut, era um pouco dessa transição do marxismo terceiro-mundista para a tendência pós-colonial, enquanto continuava ainda mais ou menos pós-marxista, interessado nos movimentos de liberação das minorias, e totalmente anti-imperialista em relação à guerra no Vietnã e às intervenções americanas na América Latina. De modo que não é como se nos movêssemos diretamente do trabalho de Fanon, Black Skin, White Masks, ${ }^{10}$ em 1952, para Orientalism, em 1978. Também, o pós-colonialismo emergiu no contexto dos Estudos Ingleses e Literatura Comparada, de maneira que 1978 marca o momento em que essas questões tomaram maior importância nesses campos, enquanto antes esse trabalho era feito nas área de História, Antropologia, Estudos Étnicos, Estudos Nativo-Americanos, Estudos Negros, Estudos Latinos e assim por diante.

ES/PS: Esta questão dialoga com os temas que vocês acabaram de levantar e com o ensaio influente de Ella Shohat, "Notes on the 'Post-Colonial'". O rótulo pós-colonial continua contestado, e seu texto é uma referência contínua para essa contestação e crítica. Apesar de os autores canônicos pós-coloniais (por exemplo, Bhabha e Spivak) serem frequentemente citados, o termo "pós-colonial" é muitas vezes rejeitado. Para esse propósito seu texto é lembrado, assim como o de Anne McClintock, " " quando são articulados por Stuart Hall em "When is the 'Post-Colonial'? Thinking at the Limit". ${ }^{2}$ Nossa pergunta para vocês dois é como vocês reavaliam o campo, à luz dos comentários do texto de Shohat, vinte anos mais tarde? Depois de tudo o que foi dito em "Notes on the 'Post-Colonial"', como vocês veem o campo?

Shohat: O pós-colonialismo foi paralelo a um pós-nacionalismo que investigou algumas das aporias do discurso nacionalista terceiro-mundista. O pós-colonial, na esteira do capítulo "The Pitfalls of National Consciousness" em The Wretched of the Earth, ${ }^{13}$ de Fanon, examinou os pontos cegos do nacionalismo em termos de gênero e etnicidade, questionando a noção de que a nação é uma coisa monolítica única. Então temos a revolução da Argélia, mas os berberes não estão incluídos, as mulheres não estão incluídas; então, este é o aspecto muito positivo dos Estudos Pós-Coloniais. 
Meu antigo ensaio "Notes on the 'Post-colonial"' era realmente sobre desempacotar o termo. Estamos mesmo "depois" do colonial, quando pensamos nos palestinos ou nos povos indígenas? Eu estava dizendo que a virada pós-colonial é uma mudança discursiva e não histórica; é o que vem depois do discurso anticolonial, depois do discurso nacionalista, terceiro-mundista e tri-continental. Nem é somente posterior, está também de fato criticando aqueles discursos. Na melhor das hipóteses, a crítica expôs pontos cegos, e na pior fez uma caricatura terceiro-mundista dicotômica, maniqueísta e daí por diante, quando argumentaríamos que, embora Fanon fosse cego para o gênero, etnicidade e sexualidade, ele não era maniqueísta. A situação colonial era maniqueísta, mas ele mesmo não. Ele também falou sobre a "ambivalência" psíquica.

Stam: E sobre a negritude, Fanon nunca foi essencialista. Au contraire. Ele enfatizou o caráter relacional, conjuntural, discursivo e constantemente em mudança da raça. Ele diria, "Na França, quanto melhor seu francês, mais branco você é", que uma pessoa - e isso fará muito sentido para os brasileiros na terra do "o dinheiro embranquece" e "brancos de Bahia" - poderia ser negra em um lugar e não ser negra em outro. Ele sempre enfatizou que a negrura e brancura existiam em "relação."

Shohat: De fato ele traz à baila o "diagnóstico situacional". Em nossas distintas publicações, citamos Fanon falando (numa nota de rodapé para Black Skin, White Masks) sobre a recepção dos filmes de Tarzan na Martinica, onde os martinicanos, que se identificam com os brancos contra os africanos, descobriram, entretanto, que, na França, os olhares hostis ou condescendentes dos espectadores brancos franceses os conscientizaram de sua própria condição de objetos do olhar ("to-be-looked-at-ness") no cinema, percebendo que eram vistos como aliados dos africanos que eles tinham visto como inimigos ao assistirem ao filme na Martinica.

Houve uma fase no início quando qualquer coisa que fosse vista como anticolonial era binário, essencialismo. É mais complicado que isso. Ainda assim, algumas coisas eram, outras não. O outro elemento que estávamos mostrando hoje ao falar

${ }^{14}$ SHOHAT E STAM, 2012. sobre o Atlântico Vermelho ${ }^{14}$ é a noção de que qualquer coisa que você irá buscar no passado torna-se um tipo de nostalgia fetichista, ou uma volta às origens e, então, um essencialismo ingênuo. Dessa forma, estávamos questionando a celebração não problematizada da hibridez, e a rejeição de qualquer busca no passado pré-colonial como uma busca ingênua de uma origem pré-lapsariana.

Stam: Também citamos o exemplo do Vídeo nas Aldeias e os Kayapós no Brasil usando câmeras para gravar e reconstituir a 
sua assim chamada cultura em extinção. Estes esforços são essencialistas? Devemos rejeitá-los em nome de nossa sofisticação pós-moderna? Isto seria obsceno, até racista da parte daqueles que não têm que se preocupar com a preservação ou ressuscitar sua cultura.

Shohat: Acho que a crítica que faço tanto no meu ensaio como em nosso Unthinking Eurocentrism ainda é válida. Mas isso não significa que não deveríamos usar o termo. Esta foi minha conclusão no ensaio que creio que Stuart Hall não compreendeu, na minha opinião, quando ele tentou dizer que eu estava de fato construindo um argumento terceiro-mundista. Eu não estava fazendo isso exatamente; era mais sobre a ideia de que nós temos que ser precisos sobre a maneira como usar essa terminologia. Não podemos simplesmente apagar o termo "TerceiroMundista" mesmo agora, se falarmos sobre uma época particular quando esse termo era usado. Ainda é relevante usá-lo para espelhar determinada terminologia de época. Se falarmos sobre o pós-colonial como termo, sim, isto também é muito problemático, porque tudo depende do que queremos dizer com isso. Nós queremos dizer pós-colonial como em pós-independência? $\mathrm{E}$, claro, então a pós-independência para a América Latina não é exatamente como a da Índia ou Iraque ou Líbano. O colonialismo acabou? De fato, não como sabemos; olhe o que vem acontecendo nos últimos dez anos em relação ao Oriente Médio etc.

Stam: Acho que um importante conceito é o de "temporalidades palimpsésticas", que significa que o mesmo lugar nacional/ transnacional pode ser simultaneamente colonial, pós-colonial e paracolonial. A relação com o povo indígena na maior parte das Américas e em Estados de assentamentos coloniais como a Austrália é ainda fortemente colonial, uma história de despossessão que continua. Olhe o impacto da represa de Belo Monte sobre o povo indígena na Amazônia, ou de represas similares no Canadá e até na Índia, onde o desenvolvimentismo nacional vai contra os interesses dos povos indígenas. Então você tem a dimensão neocolonial com a hegemonia econômica dos EUA e do Norte Global, que lentamente definha diante da "ascensão do Resto" (rise of the Rest). Agora o Brasil dá dinheiro ao FMI e Angola ajuda Portugal! Como Lula disse, "c'est tres chic!" Esse tipo de mudança econômica remodela a hegemonia. E então nós encontramos o "paracolonial" em fenômenos que existem tanto à parte como ao lado do colonial.

Acredita-se com frequência que o tema pós-colonial da "hibridez" emergiu historicamente no período do pós-guerra do carma colonial e na imigração dos anteriormente colonizados para a metrópole. Mas a hibridez sempre existiu, e apenas intensificou-se com o intercâmbio colombino iniciado pelas "viagens de descoberta". Já em 1504, o índio Carijó Essmorica 
${ }^{15}$ STAM E SHOHAT, 2012b.

${ }^{16}$ YOUNG, 2012.

${ }^{17}$ CHAKRABARTY, 2012. deixou Vera Cruz (Brasil) para a França para estudar tecnologia de armamentos na Normandia; ele, portanto, representava, avant la lettre, o índio tecnizado ou o índio high-tech de Oswald de Andrade. De forma que, quando você de fato pensa em uma duração mais longa e pensa multilocalmente, você vê esses temas de uma nova maneira.

Tudo se trata de "excesso de visão" (Bakhtin), a complementaridade das perspectivas pelas quais nós mutuamente corrigimos e suplementamos os provincianismos uns dos outros. E aqui os intelectuais do Sul Global são, em algumas coisas, menos provincianos que aqueles do Norte Global, porque são obrigados, relembrando [W.E.B.] DuBois, a ter uma dupla ou tripla consciências, são obrigados a estar atentos ao Norte e ao Sul, centro e periferia. Também há mais probabilidade de que sejam multilíngues.

Shohat: Em termos da terminologia, ainda acredito que deveríamos usar o termo "pós-colonial" de uma forma flexível e contingente. Poderia ser melhor restringir o termo "teoria póscolonial", que implica um tipo de pré-requisito de capital cultural na forma de conhecimento de pós-estruturalismo para tornarse membro do clube pós-colonial; e falar, bastante mais democraticamente, de Estudos Pós-Coloniais. Nesse momento da história, nos sentimos muito confortáveis usando o termo como uma designação conveniente para um campo particular e especialmente com as metodologias de leitura moduladas pelo pós-estruturalismo.

Stam: De fato, nós recém-publicamos um ensaio, ${ }^{15}$ uma resposta a ensaios de Robert Young ${ }^{16}$ e Dipesh Chakrabarty ${ }^{17}$ sobre 0 estado dos Estudos Pós-Coloniais. Nesse ensaio, nós elogiamos a capacidade de autocrítica dos estudos pós-coloniais e seu dom camaleônico de absorver críticas que se tornam parte do próprio campo. Então, alguns críticos dizem: "vocês não falam sobre economia política", mas daí as pessoas começam a fazer isso, nesse sentido começa a fazer parte do campo. Mas debatemos com qualquer modelo maître à penser que produza um tipo de sistema estelar que obscureça o trabalho de centenas de acadêmicos pelo mundo todo.

Shohat: E que afeta o que achamos da posição dos intelectuais brasileiros. Porque, mesmo se parte deste não foi produzido sob a rubrica dos Estudos Pós-Coloniais, ainda continua sendo, claro, muito relevante para o campo. Esses trabalhos poderiam ser abordados e recuperados dentro dessa estrutura chamada Estudos Pós-Coloniais. Portanto, não é a invenção da roda, não é voltar à estaca zero, como se não houvesse antecedentes brasileiros para tal trabalho - pense em Mário de Andrade, ou Oswald de Andrade, ou Abdias do Nascimento e Roberto Schwarz e inúmeros/ 
${ }^{18} \mathrm{GIL}, 1984$.

${ }^{19}$ VELOSO, 1997b.

${ }^{20} \mathrm{GIL}$ e VELOSO, 1993.

${ }^{21}$ VELOSO, 2001. as outros/as. Se pensarmos a partir do Sul Global, pensaremos numa maneira poliperspectiva, onde o centro é deslocado para formar múltiplos centros - por isso "policentrismo" - e com ênfase nas múltiplas diásporas e conectividades transculturais. De forma que acreditamos realmente em um pluridiálogo intelectual e em uma interlocução descentralizada através das fronteiras.

Stam: E isso também significa que os Estudos Pós-Coloniais devem ser multilíngues. Então, um dos pontos de nosso livro é "vamos falar sobre o trabalho em português e francês" e não apenas em inglês, como é muitas vezes o caso nos Estudos PósColoniais e Estudos Culturais. Temos extensas seções sobre os debates sobre raça e colonialidade no Brasil, o debate sobre ação afirmativa, e uma extensa seção sobre a Tropicália.

Quaisquer que sejam as posições de Caetano Veloso e Gilberto Gil na política local, seu trabalho em canções como "A Mão de Limpeza", ${ }^{18}$ "Manhatã", 19 e "Haiti" ${ }^{20}$ é absolutamente cosmopolita e brilhante. E você pode dançar ao som delas! Seria difícil dizer o que eu valorizo mais - um dos livros de um maître à penser ou estas músicas, que forjam ideias, mas o fazem musicalmente, liricamente, performaticamente. Como Caetano diz em "Língua", ${ }^{21}$ em uma alusão a Heidegger, "alguns dizem que só se pode filosofar em alemão, mas se você tiver uma ideia brilhante, coloque-a numa canção"! "Haiti" diz tanto sobre o Atlântico Negro, classe e raça e o que Stuart Hall disse sobre raça como a modalidade dentro da qual a classe é vivida; "Manhatã," da mesma forma, trata do que chamamos o Atlântico Vermelho, colocando cunhã - palavra Tupi para "mulher jovem" - numa canoa no Hudson. Isso conecta o Brasil indígena com a América do Norte indígena, num gesto transoceânico brilhante. Quando toco a música para meus alunos (como fizemos aqui em Utrecht), sobreponho as imagens digitais de Manahatta - o nome indígena para Manhattan, como diz Caetano em Verdade Tropical.

ES/PS: Vocês têm discutido a viagem das teorias. Dada a nova posição de hegemonia que o Brasil está ganhando internacionalmente, vocês esperam ou desejam mudanças nas dinâmicas do sistema de produção e recepção da teoria?

Stam: Acho que isso está acontecendo em parte simplesmente por causa da economia. A tal "ascensão do Resto" (rise of the Rest) significa que o Brasil... Mário de Andrade falou sobre isso. Ele disse: "nossa literatura é grande, mas ninguém sabe disso porque ter uma grande literatura é mais fácil se você também tem uma grande moeda, se você tem um grande exército." Assim, a economia afeta parcialmente, enquanto os EUA estão claramente em declínio, assim como a Europa na era da crise do euro. Isto é evidentemente, finalmente - para tocar no ponto do nacionalismo subalterno - momento do Brasil. 
22 BOURDIEU E WACQUANT, 1999.

${ }^{23}$ HANCHARD, 1994.

${ }^{24}$ Número especial da Revista Estudos Afro-Asiáticos sobre o ensaio de Bourdieu e Wacquant, "On the Cunning of Imperial Reason" (janeiro-abril 2002).

${ }^{25}$ NASCIMENTO, 1978.
Shohat: Sem dúvida o inglês continua sendo a língua franca dominante nos intercâmbios acadêmicos pelo mundo. É resíduo do colonialismo e algo não tão fácil de mudar.

Stam: Ao mesmo tempo, mesmo que isso muda vagarosamente, por exemplo, a LASA (Latin American Studies Association) e a BRASA (Brazilian Studies Association) são agora quase completamente bilíngues. Participantes facilmente vão e vêm do espanhol ao inglês ou do português ao inglês, o que não costumava acontecer.

ES/PS: Como vocês enxergam a posição atual do Brasil em relação à América do Sul e à África dentro do que vocês chamaram de "guerras culturais"?

Shohat: Talvez eu possa começar a responder à questão falando dos afro-americanos e da diáspora africana. Nosso projeto começou com a resposta de Pierre Bourdieu e Loïc Wacquan ${ }^{22} a$ um livro de Michael Hanchard, ${ }^{23}$ um cientista político afroamericano que estudou o movimento negro no Brasil. Em duas críticas, Bourdieu e Wacquant atacaram o livro como sendo um caso de exportação norte-americana do "veneno etnocêntrico" para dentro de uma sociedade brasileira completamente livre do racismo.

Stam: Não é necessário dizer que esta foi uma interpretação muito unilateral, provinciana e desinformada, que voltava ao esquema idealizado de Gillberto Freyre nos anos 1930. No Brasil, um número especial da Revista Estudos Afro-Asiático ${ }^{24}$ foi dedicado à crítica de Bourdieu/Wacquant do livro de Hanchard, que resumimos em nosso livro. Essas críticas, em geral, lamentavam a falta de conhecimento cultural do Brasil por trás dos ataques de Bourdieu/Wacquant e observaram que, embora esses autores acusem a academia norte-americana de etnocêntrica, citam, em sua refutação ao livro de Hanchard, apenas acadêmicos norte-americanos, quase não reconhecendo a longa tradição da academia brasileira nesses temas.

Shohat: Bourdieu/Wacquant insinuaram que a crítica do racismo no Brasil poderia vir apenas de fora do Brasil, quando nossas estantes tinham um sem número de livros sobre racismo e discriminação por autores como Abdias do Nascimento (Genodídio do negro brasileiro), ${ }^{25}$ Lélia Gonzales, Clóvis Moura, Sérgio Costa, Antonio Guimarães, Nei Lopes, e tantos/as outros/as.

Stam: Assim, é questão de um narcisismo branco nacionalista escondido, que projeta o racismo em um único lugar, esquecendo que a escravidão e a conquista existiram em todo o Atlântico Negro e que, como consequência, o racismo e a discriminação também podem ser encontrados em todo o Atlântico Negro. 
Shohat: Falamos em nosso novo livro de "narcisismo intercolonial" sobre a ideia de que todos os poderes coloniais, e com muita frequência seus intelectuais, querem achar que seu colonialismo, ou sua escravidão, ou sua discriminação, é melhor do que a dos outros.

Stam: Assim, a forma americana de narcisismo é dizer: "não somos colonialistas" como os outros. Apesar do colonialismo óbvio da conquista do oeste indígena do país, apesar da "farra imperial" dos anos 1890, as práticas e o imperialismo das bases militares dos EUA, eles podem invadir um país atrás do outro e sempre dizer: "Não queremos uma polegada de território da Coreia, do Vietnã, do Laos, do Camboja, de Granada, do Iraque, do Afeganistão etc." Mas continuam invadindo e mantendo as bases. Este é o narcisismo excepcionalista dos EUA. Aí temos o narcisismo francês da mission civilisatrice - "nós só nos preocupamos com cultura e educação" -, o narcisismo britânico "trata-se apenas de livre comércio" -, e o narcisismo português luso-tropicalista - "somos todos misturados e amamos as mulatas" -, então todo país tem seu excepcionalismo.

Salientamos que os intelectuais de países poderosos amam "as vítimas dos outros"; assim os alemães, historicamente, adoravam os indígenas (nativos americanos), mas não eram tão fãs dos judeus. Portanto, eles supostamente nunca teriam despossuído os nativos americanos, mas eles mataram os Hererós na África, exterminando-os em 1904. Os franceses amavam os negros americanos, mas não os árabes argelinos. Todo mundo se sente bem pensando assim. É um debate bem branco: "nós somos menos racistas que aqueles outros racistas".

${ }^{26}$ KAMEL, 2006.

Shohat: É nesse sentido que questionamos o livro popular de Ali Kamel, Não Somos Racistas. ${ }^{26}$ Ele é "global", isto é, literalmente uma das figuras importantes no mundo da Rede Globo, um imigrante sírio. É um livro jornalístico, superficial, mas sua tese é basicamente a mesma que a de Bourdieu/Wacquant. E então, claro, a resistência ao multiculturalismo e ao pós-colonialismo estava relacionada à ideia de que essas correntes teóricas só se aplicam a lugares onde você tem questóes de raça e, portanto, se aplicam aos EUA, mas não se aplica à França ou ao Brasil.

ES/PS: Sobre o tópico dos outros dos outros e da cegueira ao racismo, vocês acham a associação entre a representação do judeu e a representação do negro uma forma frutífera de descolonizar os corpos eurocêntricos da teoria?

Shohat: Definitivamente, isso é crucial e uma das discussões no nosso livro novo. Já levantamos esse tópico no Unthinking Eurocentrism e o trouxemos novamente em Race in Translation. Nos dois livros, lamentamos a segregação da questão judaica e 
${ }^{27}$ SHOHAT, 2006.

${ }^{28}$ SHOHAT, 2012.

${ }^{29}$ GODARD, 2004.x a questão colonial da raça. Para nós sempre foi importante conectar o judeu, o muçulmano e o negro africano diaspórico a esses debates. Todos esses assuntos podem ser encontrados nos vários eventos de 1492, a Inquisição, a expulsão dos mouros, a "descoberta", isto é, a conquista das Américas e os primórdios da escravidão transatlântica, primeiro dos índios, depois dos africanos. Todos aqueles tópicos estavam relacionados na ocasião, e ainda estão relacionados agora. Com relação aos judeus e aos negros - e certamente esta não é uma oposição simples já que muitos judeus são negros - iemenitas, etíopes, convertidos etc. - e muitos negros são judeus. Não é por acaso que o movimento ativista sobre judeus árabes em Israel se autodenominam Panteras Negras. Mas essa discussão remonta há muito tempo. Apenas no período do pós-guerra, Fanon, em Black Skin, White Masks, começa a pensar sobre a racialização do negro em relação ao judeu. Em Race in Translation, temos uma discussão desse estudo comparativo do judeu e do negro, e em Taboo Memories um ensaio enfoca essa questão em detalhe. ${ }^{27}$ Mas em nosso livro mais recente nós ligamos a questão judaica com a questão muçulmana/árabe, porque Fanon também fala sobre o árabe, e ele não idealizou nenhum grupo. Ele diz: "O árabe é racista em relação ao negro, o judeu é racista em relação ao negro". Ele observou que na França era mais fácil ser negro que árabe, e cita exemplos onde a polícia o teria assediado, e depois se desculpado ao descobrir que ele não era árabe, mas um caribenho. O que complica a relação, como vimos ontem em Forget Baghdad, ${ }^{28}$ é toda a questão de Israel, o sionismo como um projeto de branqueamento e europeização do judeu. Vemos isso na história do cinema sionista e mais tarde no cinema israelita, onde a escolha do elenco sempre favorece atores loiros de olhos azuis, o judeu musculoso, culminando com o filme Exodus, onde você tem Paul Newman sendo lançado como um novo tipo de judeu, o oposto polar do judeu da diáspora, shtetl, do gueto, vitimizado. De certa forma, os judeus internalizaram os discursos antissemitas.

ES/PS: É o problema da nação entrando no que poderia ser um campo potencialmente liberador do pós-colonial?

Shohat: Embora seja possível dizer que a maioria dos estadosnação é anômala, Israel é, talvez, mais anômalo que outros. É uma formação mista, por um lado representa um projeto nacionalista -e, portanto, análogo às lutas do Terceiro Mundo e de minorias -, mas do ponto de vista palestino, também é um projeto de assentamento colonial, e é por isso que os palestinos se veem como indígenas, comparáveis aos nativos americanos, um ponto levantado por Godard no filme Notre Musique, ${ }^{29}$ que faz essa analogia diretamente. De fato, o filme liga os vários temas - antissemitismo, nativos americanos, judeus, palestinos 
etc. - fazendo os personagens nativo-americanos articularem a analogia. O filme se passa também em Sarajevo, uma sociedade multicultural parcialmente muçulmana e distantemente judaica, sitiada pelos ortodoxos nacionalistas sérvios. (Há até uma história sobre muçulmanos na Bósnia protegendo a Torá, mesmo depois de os judeus terem partido.) Os palestinos, no filme, citam o poema The Red Indian, de Mahmoud Darwish. ${ }^{30}$

Stam: Ao mesmo tempo, os americanos nativos se identificam com os judeus como sendo vítimas do Holocausto. Alguns americanos nativos, como Ward Churchill, que escreveu uma sinopse para nosso livro, alega provocativamente que "Colombo foi nosso Hitler", e aqui Churchill foi atacado pelas organizações judaicas nos EUA: "Como ele pode comparar Hitler a Colombo... não houve genocídio... não foi intencional, eles apenas pegaram doenças" etc. Mas, de fato, houve um megagenocídio, um tanto causado por doenças, mas também pelos massacres já relatados por [Bartolomé] de las Casas no século XVI, que continuou até o século XX (por exemplo, na Guatemala e em El Salvador).

Shohat: Churchill também foi acusado - assim como muitos outros escritores, como Edward Said - de "inveja narrativa" em relação à narrativa de vitimização judaica.

Stam: E na França esse debate tem sido muito intenso, envolvendo muitos escritores de diferentes contextos e envolvendo um grande número de posicionamentos. Há pensadores judeus, como Alain Finkielkraut, vagamente associados à esquerda dos anos 1960, que mais tarde se tornaram antinegros, anti-Terceiro Mundo e antipalestinos. Por outro lado, temos pensadores judeus muito progressistas, como Edgar Morin e Esther Benbassa, que dizem: "Não, nós temos estado simbioticamente ligados aos muçulmanos historicamente." Observamos o que chamamos de "virada para a direita" de muitos judeus sionistas nos EUA e na França e em muitos outros países. Vale notar que Claude Lanzmann, o autor de Shoah, ${ }^{31}$ mas também de documentários militantemente pró-israelitas, não foi sempre tão fervorosamente sionista ou antipalestino.

Em 17 de outubro de 1961, quando a polícia francesa assassinou (obedecendo ordens do Chefe de Polícia Maurice Papon - e aqui novamente vemos a ligação entre as atitudes antimuçulmanos e antissemitas -, o mesmo homem que mandou judeus para os campos de extermínio) duzentos ou mais argelinos nas ruas de Paris, Claude Lanzmann escreveu uma declaração pública dizendo: "Nós, como membros da comunidade judaica, entendemos o que vocês estão passando. Sabemos o que significa ser acossado e assassinado por causa de sua identidade. Sabemos o que isso significa." De forma que, nessa época, havia solidariedade. Foi apenas depois de 1967 que há uma polariza- 
${ }^{32}$ SARTRE, 1948.

${ }^{33}$ SARTRE, 1978.

${ }^{34}$ The Question teve sua primeira publicação no Reino Unido. Logo depois de "Une Victoire", de Sartre, uma nova edição foi publicada em francês por Les Éditions de Minuit.

${ }^{35} \mathrm{Em} 10$ de novembro de 1975, a Assembleia Geral das Nações Unidas adotou a Resolução 3.379, onde se lê na conclusão: "O sionismo é uma forma de racismo e discriminação racial". Depois de anos de pressão dos EUA e de Israel, em 16 de dezembro de 1991, a Assembleia Geral da ONU revogou a Resolução 3.379.

${ }^{36}$ Comunidade dos Países Africanos de Língua Portuguesa. ção radical, generalizada, entre judeu e árabe (e, é evidente, alguns judeus são árabes).

Fanon, da mesma forma, tinha alertado seus colegas negros "quando as pessoas estão falando de judeus, estão falando de vocês". Vocês sabem, "vocês serão os próximos", ou, "é o mesmo processo". No âmbito da academia, enquanto isso, o primeiro trabalho sobre racismo na Europa e nos EUA, por exemplo, foi sobre o antissemitismo. "O Holocausto aconteceu, o que levou a isso?" Assim você tem análises da "personalidade autoritária" e assim por diante. É apenas mais tarde que a discussão muda para a raça.

Shohat: A aliança negro-judaica se desfez em grande parte no despertar da vitória israelita, e nos EUA no despertar das lutas pelas autonomias das escolas, da Palestina e de outras questões; com Jean-Paul Sartre escrevendo na França sobre o Anti-Semite and the Jew, ${ }^{32}$ mas também mais tarde publicando no L'Express "Une Victoire", ${ }^{33}$ que é sobre Henri Alleg, um comunista judeu que se juntou à luta anticolonial argelina contra os franceses e se tornou prisioneiro, sendo torturado, o que o levou ao seu livro censurado sobre tortura chamado La Question. ${ }^{34}$ Sartre, que também tinha escrito a introdução ao livro de Fanon, The Wretched of the Earth, viu a questão da tortura como parte do mesmo contínuo de luta. Mas isso mudou depois de 1967, quando Josi, a esposa de Fanon, que ainda vivia na Argélia, explicou que ela não queria a inclusão da introdução de JeanPaul Sartre na nova edição de The Wretched of the Earth porque ele tomou uma posição pró-Israel, portanto mostrou que apoiava o colonialismo. Em contraste, Jean Genet apoiou não apenas os Panteras Negras nos EUA, mas também os palestinos.

O ano de 1967 marca uma divisão, em que alguns judeus deram o que chamamos uma "virada para a direita", se dissociado da coalisão na luta terceiro-mundista (posteriormente multicultural), embora muitos judeus continuassem a ser aliados dos TerceiroMundistas e das lutas minoritárias. Mas no início dos anos 1980, no despertar da proclamação "Sionismo é Racismo" nas Nações Unidas, ${ }^{35}$ muitos judeus da esquerda começaram a virar para a direita porque associaram o Terceiro-Mundismo e posteriormente o multiculturalismo com "anti-Israel" e até com posições antissemitas.

ES/PS: Continuando dentro da geopolítica e voltando ao Brasil, como vocês veem a posição do país em relação a outras regiões (formalmente) subalternas, quando o país emerge como um poder potencialmente hegemônico? Por exemplo, o Brasil tem investido em países africanos e está voltando sua atenção aos países africanos que têm o português como sua língua oficial através da CPLP. ${ }^{36}$

Shohat: Bem, certamente o Brasil, que é um país enorme e a sexta economia do mundo, tem um desejo legítimo de ser reconhe- 
cido como um poder global. Isso já estava claro desde que o Brasil mostrou o desejo de se tornar membro do Conselho de Segurança da ONU. O próprio fato de Sérgio de Mello ter sido escolhido como representante brasileiro no Iraque - com trágicas consequências - também representou algo muito positivo para o Iraque. Mas o Brasil tem, em certos momentos, jogado um papel ambíguo e confuso no Oriente Médio, como quando vendeu, não diferentemente dos EUA, aviões para o Iraque durante a era de Saddam Hussein. Hussein era um ditador fascista, não muito diferente da junta militar do Brasil. O fato de ser totalmente contra a invasão americana do Iraque não me impede, como uma judia árabe-iraquiana, de denunciar Hussein de ditador. Mas, em geral, achamos que o Brasil, ao contrário dos EUA, que está sempre vendendo armas, tem sido uma força pacificadora no mundo.

Stam: Nós também temos a questão, claro, da negritude e da identidade negra em relação à África e à diáspora africana. Por um lado, você tem a economia brasileira se expandido para a África. Você vê também cada vez mais estudantes africanos vindo de Angola e Moçambique para as universidades brasileiras, um fenômeno que também se vê nos EUA, com o que se chama os neoafricanos do Senegal, Nigéria, Quênia e assim por diante. Tanto no Brasil quanto nos EUA, vocês têm o problema dos sistemas educacionais eurocêntricos que tendem a tratar a África, quando não a ignoram totalmente, como um continente vítima, um continente de escravos, sem qualquer história autônoma. Essas ideias foram desafiadas por muitos acadêmicos nos dois países, por exemplo, pessoas como [Luiz Felipe de] Alencastro, que estuda o Atlântico Sul de forma a enfatizar o agenciamento africano.

ES: Recentemente, políticas de ações afirmativas estão ganhando terreno no Brasil, para, de alguma forma, tentar um ajuste de contas com o estado subalterno dos descendentes de africanos; mas não há uma real memória pública sobre a violência perpetrada contra os indivíduos negros durante e depois da colonização.

Shohat: A questão é: dentro de que tipo de metanarrativa? É a narrativa de trazer a modernidade para a África? É o mesmo tipo de narrativa de resgate? O Brasil deverá ser visto agora quase como o país ocidental em relação à África "atrasada"? A reação surpresa de Lula em relação à modernidade da África - "nem

${ }^{37}$ Lula notoriamente declarou, quando da sua chegada em Windhoek (Namíbia) em 2003, que a capital era tão limpa, bonita e com povos tão extraordinários que ele nem sentia que estava em num país africano. parece a África!" ${ }^{37}$ - é, nesse sentido, sintomática. À parte o candomblé, e a capoeira e os blocos afro - que também são muito importantes -, como a África aparece no discurso político brasileiro contemporâneo? Estas seriam questões cruciais para considerarmos dentro da nossa forma de pensar.

Stam: Um dos argumentos de nosso novo livro é a interconectividade transnacional em termos do intercâmbio de ideias. Por 
${ }^{38}$ AZULAY, 1996.

${ }^{39}$ SCHWARTZ, 1973.

exemplo, o Brasil e os EUA têm estado ligados desde o início. A palavra "negro", em inglês, vem do português. Alguns dos primeiros negros em Manhattan eram afro-brasileiros de origem bantu, cujos nomes - Simon Congo, Paulo d'Angola - revelam suas origens. Os holandeses, em sua luta contra os americanos nativos e os britânicos, decidiram ter alguns negros com eles, provindos das áreas portuguesas, e dar-lhes liberdade e terras em troca de que lutassem contra os britânicos. Por exemplo, o terreno onde está o SOBs (Sounds of Brazil/Sons do Brasil), o clube noturno onde músicos brasileiros como Gilberto Gil, Martinho da Vila e Djavan sempre tocam, pertenceu, numa continuidade incrível, a Simon Congo.

Shohat: A conexão Nova lorque/Brasil também envolve os judeus do Recife que vieram para a então chamada Nova Amsterdã com os holandeses para fundar a primeira sinagoga em Nova lorque. Sempre esquecemos que a Inquisição continuava nas Américas, inclusive no Brasil. Um filme lusobrasileiro chamado O Judeu, de Jom Tob Azulay, ${ }^{38}$ fala sobre essa relação. De forma que os holandeses não tiveram Inquisição, e, de fato, uma porção de judeus portugueses veio para cá [para a Holanda], Spinoza, etc. No norte do Brasil, em Pernambuco, a dominação holandesa foi um refúgio para muitos judeus perseguidos, e quando a Nova Amsterdã acontecia, e com a retirada dos holandeses de Pernambuco, eles foram para a Nova Amsterdã, que é Nova lorque, e eis por que a primeira sinagoga em Nova lorque é uma sinagoga portuguesa, por causa dos judeus que vieram de Pernambuco.

Stam: E essa sinagoga foi o primeiro lugar no que hoje são os EUA a ensinar a língua portuguesa. A propósito, há outra expressão em inglês, pickaninny, para se referir a uma criança pequena negra, que vem do português "pequenino." Assim, através da língua você vê certa interconexão cultural, apesar do mito da separação.

Shohat: Eis por que a tradução também foi um tema-chave para nós. Não somente a tradução literal, mas também como um tropo para evocar toda a fluidez e as transformações e indigenizações que ocorrem quando as ideias "fora de lugar"39 cruzam as fronteiras e viajam de um lugar a outro. Também na vida intelectual navegar é preciso.

ES/PS: A raça, entretanto, geralmente não é um tema, uma questão nos Estudos de Tradução Cultural, que se tornou uma importante área de conhecimento. Foi essa ausência que motivou a sua escolha do título Race in Translation para seu livro? É uma provocação? 
Stam: Na verdade, não. Tentamos tantos títulos, de maneira que foi quase por acaso que a raça acabou ficando tão destacada.

Shohat: Nós, na verdade, tínhamos pensado em Cultural Wars in Trans/ation originalmente, mas a editora não gostou, achou muito pesado, então ficamos com Race in Trans/ation. De fato, a raça tem sido um tema comum nos Estudos Culturais - incluindo autores como Stuart Hall - geralmente como parte do "mantra" (classe, raça, gênero, sexualidade etc.). No campo dos Estudos Pós-Culturais, você encontra raça como tema através das referências a Fanon, mas é, às vezes, considerado menos importante por estar muito atado às "políticas identitárias", supostamente desconstruídas pela teoria pós-estruturalista. Os Estudos Pós-Coloniais, desde nosso ponto de vista, são às vezes um tanto condescendentes em relação às várias formas dos Estudos Étnicos e Estudos de Área (Estudos Nativo-Americanos, Estudos Afro-Diaspóricos, Estudos Latinos, Estudos LatinoAmericanos, Estudos do Pacífico, Estudos Asiáticos etc.), ignorando sua contribuição, inclusive as formas através das quais os Estudos Étnicos abriram a academia para que os Estudos Pós-Coloniais tivessem um espaço tão importante.

Stam: O pós-colonialismo, às vezes, se apresenta como teoricamente sofisticado, enquanto os Estudos Étnicos são injustamente apresentados como tendo pouca aura e prestígio teórico. A escrita afro-americana também é teórica; não é como se só um lado fosse teórico. Nos EUA esses temas também ficam amarrados nas tensões entre os imigrantes, inclusive imigrantes africanos, que se saem muito bem, enquanto os afro-americanos ainda permanecem oprimidos e marginalizados, mesmo apesar da vitória do Obama. Você tem imigrantes da Índia que são prósperos e às vezes bastante conservadores, e você tem americanos negros que estão nos EUA há séculos e não estão tão bem. Pode-se até encontrar tensões entre os afro-americanos e os africanos, e entre os negros nascidos nos EUA e os negros caribenhos, porque os caribenhos são às vezes retratados como "a boa minoria", como os asiáticos (esta mesma divisão se vê na França). As pessoas não sabem disso, mas os imigrantes com maior escolaridade nos EUA são os africanos. O que é uma pena para a África, é a fuga de cérebros, mas é uma bênção para os EUA. Mas nenhum deles, inclusive os intelectuais francófonos, conseguem trabalho na França. Então seguem para o Canadá, para os EUA e para a Inglaterra, mas não para a França, em parte porque a França, apesar do protagonismo dos escritores francófonos em todos esses movimentos, além de ter um sistema acadêmico relativamente fechado, esteve refratária aos Estudos Culturais, Estudos Étnicos e aos Estudos Pós-Coloniais. Mas também observamos que houve uma grande explosão de literatura sobre essas questões durante o século XXI, especial- 
${ }^{40}$ NDIAYE, 2008.

mente depois das revoltas no banlieue, em 2005. Agora encontramos Estudos Negros à la française no livro de Pap Ndiaye, La Condition Noire. ${ }^{40}$

Shohat: Mas a resistência aos Estudos Pós-Coloniais e Multiculturais às vezes vem dos radicais esquerdistas leninistas, como [Slavoj] • $ं \bullet e k$, que ataca o multiculturalismo e a política de identidade de uma maneira muito pouco esclarecida (obviamente ele não leu o tipo de trabalho sobre o qual falamos). Deve-se perguntar por que a direita (Bush, Cheney, Cameron, Sarkosy, Merkel) e alguns esquerdistas se opõem às políticas de identidade hoje em dia, embora obviamente não pelo mesmo ângulo.

Stam: E, de certa forma, tem a ver com argumentos de que classe é mais relevante que raça, e que economia é mais relevante que cultura. Porque a "briga real é com capitalismo global", não vamos nos deixar distrair com temas feministas, assédio policial, pessoas negras marginalizadas, latinos nos EUA, descendentes de árabes/ muçulmanos na França, indígenas e negros no Brasil etc.

Shohat: Um assunto no qual os Estudos Pós-Coloniais são muito valiosos é na crítica das premissas que apoiam os Estudos de Área, que, diferentemente dos Estudos Culturais, foram uma criação muito de cima para baixo na política exterior dos EUA, e que, com frequência, separam a América Latina (lá) e as pessoas latinas que moram nos EUA (aqui), o Oriente Médio (lá) e as pessoas do Oriente Médio (espalhadas pelas Américas, inclusive no Brasil, onde sempre se diz que já há mais libaneses que no próprio Líbano). Uma antologia que coeditei, que deve sair em breve, trata desse tópico. De forma que o que queremos é colocar essas coisas juntas, porque os Estudos de Área segregam, problematicamente, esse fluxo global de pessoas, de ideias, de culturas, se não olham para os movimentos diásporicos de ida e vinda.

Stam: Encontramos uma segregação eurocêntrica semelhante na maneira como se reconta a história. A maioria dos livros sobre a revolução e a "era da revolução" nunca fala sobre o Haiti, que foi a mais radical das revoluções, porque foi nacional, social, antiescravagista etc... e lembramos a nossos leitores que a primeira "pós-colônia" e "neo-colônia" foi o recém-independente Haiti. Em 1804, a França os puniu por derrotarem o exército francês, deixando-os com enormes dívidas. O FMl da época era a França. Mais tarde, os EUA invadiram o Haiti, e a França e os EUA colaboraram para depor Aristide. Eis por que o Haiti é tão pobre.

PS: Os latino-americanos e os caribenhos, apesar do entusiasmo pelos conceitos, frequentemente expressam ambivalência com relação aos Estudos Pós-Coloniais e a teoria. Onde está a América Latina nesta discussão? 
${ }^{41}$ STAM E SHOHAT, 2011.
Stam: Sim, a perspectiva não deveria ser a de "os pós-coloniais estão lá, e nós os atacamos". Não, somos parte disso e isso é parte de nós, e contribuímos, mas acho que muitos latinoamericanos têm esta reserva: "E a América Latina?" Mas de certa maneira, devemos fazer nosso trabalho, e não só reclamar do que os Estudos Culturais não estão fazendo. No final das contas, somos parte dos Estudos Pós-Coloniais.

ES/PS: Em seu capítulo em Europe in Black and White, ${ }^{41}$ vocês alertaram contra as "grandes narrativas comparativas" na crítica pós-colonial, que impôs rotas de viagem "dentro de geografias culturais rigidamente imaginadas". Em sua opinião, quais ideias, conceitos e teorias não estão viajando o bastante?

Shohat: Acho que nos falta, em certas geografias de teorias viajantes, esta questão de fazer conexões, o método de fazer conexões e o que enfatizamos como analogias associadas (linked analogies). Sempre fomos contra certo tipo de abordagem isolacionista e baseada no estado-nação, e muito mais a favor de uma abordagem ampla, multidirecional, mais relacional.

Stam: Mas em nosso livro recente nos limitamos ao que conhecemos - França, Brasil e EUA (e para Ella, o Oriente Médio, embora eu conheça um pouco sobre a regiáo por ter vivido no norte da África, e agora em Abu Dhabi). Poderia defender-se os estudos Sul-Sul, por exemplo, incluindo Índia e Brasil como países multiétnicos, multirreligiosos do Sul Global. Sempre nos ocorre que as teorias brasileiras sobre cinema poderiam ser muito relevantes para o cinema indiano. Na Índia você tem este binarismo, para os intelectuais, da "má Bollywood" e do "bom filme de arte", enquanto os brasileiros já estavam questionando essa hierarquia nos anos 1970, vendo as chanchadas de uma forma positiva. Tropicália, Carmen Miranda, etc... Então acho que muitos lugares poderiam aprender com o Brasil, e é por isso que as pessoas afirmam que o Brasil foi pós-moderno avant la letre. A Tropicália estava questionando a alta e baixa cultura, incorporando a cultura global da mídia, promovendo sincretismos. Em termos de sincretismo, você vê o romance Macunaíma, ${ }^{42}$ de 1928, que era, o próprio, racialmente múltiplo, e que criou um personagem "sem nenhum caráter." 0 personagem constantemente muda como um camaleão. Se isso não for hibridez pós-colonial, então não sei o que é.

Shohat: O problema é que esse tipo de conhecimento e análise tende a limitar-se aos Estudos Brasileiros, apesar de ser relevante para todo o mundo. Então o Brasil, a cultura brasileira e os Estudos Brasileiros não estão viajando bastante. Todo país que se rebelou contra o colonialismo produziu sua porção de pensamentos e arte, inclusive o mundo árabe, a Ásia e o mundo indígena. 
${ }^{43}$ VELOSO, 2007.

${ }^{44}$ VELOSO, 1993.
Stam: Todo país deveria ser parte do debate pós-colonial. Agora é hora de países como o Brasil ser fonte de ideias "fora de lugar"! Mas, mesmo que o Brasil esteja emergindo como uma espécie de poder econômico global, permanece marginalizado como poder cultural/filosófico, considerado ainda, com frequência, irrelevante para os Estudos Pós-Coloniais e Estudos Culturais.

Shohat: Dessa forma, para nós, não se trata apenas de multiplicar geografias, mas também de multiplicar as rubricas e teorias e perspectivas para que se possa ver relacionalidades e analogias associadas. Tome qualquer lugar do planeta como exemplo: falar do Vietnã é falar do imperialismo francês e americano; é vêlo em relação ao Senegal e Tunísia como colônias francesas também, ou, em relação à França e aos EUA, como poderes coloniais/imperiais. Mas não tem que passar por um centro, e é por isso que defendemos no início de Unthinking Eurocentrism o policentrismo e multiperspectivalismo, com uma abertura do tipo cibernética de pontos de entrada e partida, enquanto reconhecendo também as assimetrias e as desigualdades geopolíticas.

Stam: Parte do tema do nosso livro novo é defender os intelectuais brasileiros, sugerindo que Roberto Schwarz, Ismail Xavier, Haroldo de Campos, Sérgio Costa e Abdias do Nascimento são tão interessantes quanto Fredric Jameson ou Pierre Bourdieu. Não é uma hierarquia. Eles todos deveriam estar traduzidos. Falamos sobre o fato de que os intelectuais brasileiros tendem a conhecer os franceses e os americanos, mas quantos franceses e americanos conhecem os escritores brasileiros?

A cultura popular brasileira é outra história, mas esta também deveria ser mais bem conhecida, dado que a música brasileira, por exemplo, que é tão surpreendentemente erudita e sofisticada, e popular ao mesmo tempo. Caetano Veloso, por exemplo, dialoga com o ensaio de Roberto Schwarz em Tropicália, respondendo: "Brasil é absurdo mas não é surdo."43 Em quantos lugares do mundo músicos populares falam de Heidegger em suas canções, ou escrevem uma história lírica de um movimento de cinema como o faz Caetano em "Cinema Novo?" 44 Ou intelectuais literários como Zé Miguel Wisnik, que compõe sambas eruditos e toca as composições de Scott Joplin de trás para a frente! Para nós, a música e a arte podem, muitas vezes, dizer tanto quanto a literatura acadêmica.

ES/PS: O Atlântico é um tropo recorrente nas analogias comuns e rotas frequentes das viagens das ideias. Vocês consideram 0 Atlântico, tanto quanto a lusofonia, por exemplo, uma grande narrativa comparativa que domina o campo pós-colonial? É possível apropriar-se delas e usá-las produtivamente ou deveríamos ter como objetivo nos livrarmos delas em momento oportuno? 
${ }^{45}$ Clifford faz um trocadilho com as palavras em inglês routes (rotas) e roots (raízes). N.R.
${ }^{46}$ CLASTRES, 1987.
Shohat: Talvez a lusofonia tenha sido visível nos Estudos PósColoniais por causa da questão do Atlântico Negro e a escravidão, mas de fato, se pensarmos no "mundo lusófono", teremos que relacioná-lo com a Índia, Goa, Oceano Índico, Macau e mesmo os resíduos dos assentamentos portugueses no que hoje é Abu Dhabi, essas áreas, a área do Golfo.

Stam: Em Race in Translation, observamos a explosão de metáforas aquáticas para falar desses temas - Atlântico Negro (nós falamos do Atlântico Vermelho), performance circum-Atlântica (Roach), tidalectics [dialética que segue o movimento das marés] (Kamau Brathwaite), modernidade líquida (Bauman) - como forma de encontrar uma linguagem mais fluida que vai além da rigidez das fronteiras do estado-nação. Não é o caso de "se livrar de", mas de expandir, para ver as correntes do Atlântico alimentarem o Pacífico.

Shohat: Temos os Estudos do Pacífico, os Estudos do Oceano Índico, Estudos Mediterrâneos, e mesmo os Estudos do Delta e Estudos Insulares. Um artigo recente enfatizou que Obama era um ilhéu - Havaí, Indonésia, Manhattan! Também é uma questão de modéstia. Não podemos saber tudo - o Atlântico Negro, o Vermelho e o Branco já são assuntos enormes. De maneira que a questão é fazer conexão com outras correntes. Françoise Vergès, que nasceu em Reunion, mas foi para a Argélia para se juntar à Revolução, e depois estudou nos EUA e na França, mas dá aulas na Inglaterra - portanto encarnando esta abordagem transnacional -, sempre afirma que a escravidão penetrou Reunion; o colonialismo esteve em toda parte; portanto, onde os viajantes passavam, deixavam suas marcas. De fato o que é útil aqui é a metáfora de rotas ${ }^{45}$ de James Clifford. Rotas [routes/roots] são também oceânicas, então são importantes. Mas não é para substituir a terra. Não é uma questão de ou-ou; é uma questão de foco e abertura para novos conhecimentos, línguas, perspectivas.

ES/PS: Vocês falaram sobre o "Atlântico Vermelho" e as epistemologias indígenas viajando entre a Europa e as Américas indígenas. Poderiam elaborar a ideia?

Stam: Sim, mostramos que tem havido cinco séculos de interlocução filosófica/literária/antropológica entre os escritores franceses e os índios brasileiros, entre os franceses protestantes, como Jean de Léry; entre três índios Tupinambás na França e Montaigne, até chegarmos a Lévi-Strauss - que trabalhou com os Nambiquaras - e Pierre Clastres ("Society against the State") ${ }^{46}$ e René Girard (que fala sobre o canibalismo Tupinambá), e, na corrente contrária, Eduardo Viveiros de Castro, que vê os índios da Amazônia através de uma perspectiva deleuziana. Começamos a encontrar um diálogo mais equitativo entre os intelectuais ocidentais e os 
${ }^{47}$ GRANDE, 2004.

${ }^{48}$ SANTOS, 1971. pensadores nativos. Por exemplo, Sandy Grande é uma Quéchua do Peru, que dá aulas numa universidade americana. Ela escreveu um livro chamado Red Pedagogy, ${ }^{47}$ que é um diálogo crítico com os defensores mais radicais, marxistas, feministas, revolucionários e multiculturais de uma pedagogia radical do tipo freiriano, mas ela fala em pé de igualdade e mesmo como crítica, dizendo que eles têm muito o que aprender com os povos indígenas. Os intelectuais nativos e produtores de mídia circulam internacionalmente. Cineastas Caiapós - que não podiam viajar com passaportes até a constituição brasileira de 1988 - encontram-se com os cineastas aborígenes australianos e indígenas do Alasca em festivais de Nova lorque e Toronto. Davi Yanomami relata o massacre dos lanomâmis fora do Brasil. Raoni e Sting se reúnem com François Mitterrand nos anos 1980. Já no século XVI, Paraguaçu se encontrou com a realeza francesa. No século XVII, Pocahontas reuniu-se com a realeza britânica e com dramaturgos como Ben Jonson.

Esquecemos que, nos primeiros séculos de contato, líderes nativos como Cunhambebe (retratado em Como Era Gostoso Meu Francês) ${ }^{48}$ eram recebidos como membros da realeza pelos franceses. Esquecemos que os Tupinambás foram a Rouen para se apresentar para o Rei Henrique II e Catarina de Médici, fato que foi celebrado por uma escola de samba nos anos 1990. Temos um presidente Aimará na Bolívia, Evo Morales, que apareceu - para delírio da multidão - no programa Jon Stewart Daily Show. Alguns países andinos incluíram em suas constituições "o direito da natureza de não ser agredida". Assim, sem ser eufórico, já que sabemos que as coisas não vão exatamente bem para os povos indígenas, há, por outro lado, contracorrentes muito importantes.

\section{Referências}

ABDEL-MALEK, Anouar. "L'Orientalisme en crise". Diogène, n. 44, p. 109-142, 1963.

ANDRADE, Mário de. Macunaíma, o herói sem nenhum caráter. São Paulo: Oficinas Gráficas de Eugenio Cupolo, 1928.

AZULAY, Jom Tob (Dir.). O judeu. Tatu Filmes, Metrofilme Actividades Cinematográficas, A\&B Produções, 1996. Filme.

BOURDIEU, Pierre, and WACQUANT, Loïc. "On the Cunning of Imperial Reason." Theory, Culture, and Society, v. 16, n. 1, p. 41-58, 1999. [Publicado no Brasil como "Sobre as artimanhas da razão imperialista". Estudos Afro-Asiáticos, v. 24, n. 1, p. 15-33, 2002.]

BUARQUE, Chico; GIL, Gilberto. "Cálice". Chico Buarque. Philips, 1978. LP.

CHAKRABARTY, Dipesh. "Postcolonial Studies and the Challenge of Climate Change". New Literary History, v. 43, n. 1, p. 1-18, 2012. 
CLASTRES, Pierre. Society against the State: Essays in Political Anthropology. Trans. Robert Hurley and Abe Stein. New York: Zone Books, 1987.

DARWISH, Mahmoud. "The Speech of the Red Indian". Trans. Sargon Boulos. In: AKASH, Munir, and MOORE, Daniel (eds.). The Adam of Two Edens: Poems. Syracuse: Syracuse University Press, 2000. p. 129-145.

FANON, Frantz. The Wretched of the Earth. Trans. Constance Farrington. New York: Grove Press, 1965. [Publicado no Brasil como Os condenados da terra. Trad. José Laurênio de Melo. Rio de Janeiro: Editora Civilização Brasileira, 1968.]

Black Skin, White Masks. New York: Grove Press, 1967. [Originalmente publicado por Editions de Seuil, France, 1952.] [Publicado no Brasil como Pele negra, máscaras brancas. Trad. Renato da Silveira. Salvador: EdUFBA, 2008].

GIL, Gilberto. "Mão de Limpeza". Raça Humana. WEA, 1984. LP.

GIL, Gilberto; VELOSO, Caetano. "Haiti". Tropicálica 2. Universal, 1993. CD.

GRANDE, Sandy. Red Pedagogy: Native American Social and Political Thought. Lanham, MD: Rowman \& Littlefield, 2004. GODARD, Jean-Luc. Notre Musique. Wild Bunch, 2004. Filme.

HALL, Stuart. "When was the 'Post-Colonial'? Thinking at the Limit". In: CHAMBERS, lain, and CURTI, Lidia (eds.). The Post-Colonial Question: Common Skies, Divided Horizons. London: Routledge, 1996. p. 242-260. [Publicado no Brasil como "Quando foi o pós-colonial? Pensando no limite". In: Da diáspora: identidades e mediações culturais. Org. Liv Sovik. Belo Horizonte: Editora UFMG, 2003.]

HANCHARD, Michael George. Orpheus and Power: The "Movimento Negro" of Rio de Janeiro and São Paulo, Brazil, 1945-1988. Princenton: Princenton University Press, 1994. [Publicado no Brasil como Orfeu e o poder: movimento negro no Rio e São Paulo (1945-1988). Trad. Vera Ribeiro. Rio de Janeiro: EdUERJ, 2001.]

KAMEL, Ali. Não somos racistas: uma reação aos que querem nos transformar numa nação bicolor. Rio de Janeiro: Nova Fronteira, 2006.

LANZMANN, Claude. Shoah. New Yorker Films, 1985. Filme.

MCCLINTOCK, Anne. "The Angel of Progress: Pitfalls of the Term 'Post-Colonialism'”. Social Text, n. 31/32, p. 84-98, 1992.

NASCIMENTO, Abdias do. O genocídio do negro brasileiro: processo de um racismo mascarado. Rio de Janeiro: Paz e Terra, 1978.

NDIAYE, Pap. La Condition Noire. Paris: Calmann-Lévy, 2008.

ROCHA, Glauber. Terra em transe. 1967. Filme.

SAID, Edward W. Orientalism. New York: Pantheon Books, 1978. [Publicado no Brasil como Orientalismo: o Oriente como invenção do Ocidente. Trad. Tomás Rosa Bueno. São Paulo: Companhia das Letras, 2003.] 
SANTOS, Nelson Pereira dos. Como era gostoso meu francês. Regina Films, New York Films, 1971. Filme.

SARTRE, Jean-Paul. Anti-Semite and Jew. Trans. George Joseph Becker. New York: Schocken Books, 1948.

. "Une Victoire". Situations V: Colonialisme et NéoColonialisme: 1958. Paris: Gallimard, 1978.

SCHWARTZ, Roberto. "Idéias fora do lugar". Estudos Cebrap, n. 3, p. 150-161, 1973.

SHOHAT, Ella. "Notes on the 'Post-Colonial'”. Social Text, n. 31/32, p. 99-113, 1992.

. Taboo Memories, Diasporic Voices. Durham: Duke University Press, 2006.

. "Postcolonial Cinema Studies Conference Session: Forget Baghdad: Jews and Arabs - the Iraqi Connection (Dir. Samir, 2003)". Organizado por Sandra Ponzanesi, Utrecht University, em colaboração com Postcolonial Studies Initiative, Centre for the Humanities, Culture \& Identities and the Gender Studies Programme. Utrecht. 7 June, 2012.

SHOHAT, Ella, and STAM, Robert. Unthinking Eurocentrism: Multiculturalism and the Media. New York: Routledge, 1994. [Publicado no Brasil como Crítica da imagem eurocêntrica: multiculturalismo e representação. Tradução: Marcos Soares. São Paulo: Cosac Naify, 2006.]

. "Race in Translation. Cultural War around the Postcolonial Atlantic". Utrecht University Postcolonial Studies Initiative Doing Gender Lectures. Utrecht. 8 June, 2012.

STAM, Robert, and SHOHAT, Ella. "The Culture Wars in Translation". In: SANCHES, Manuela Ribeiro et al. (eds.). Europe in Black and White: Interdisciplinary Perspectives on Immigration, Race and Identity in the "Old Continent". Chicago: Intellect, 2011. p. 17-35.

. Race in Translation: Culture Wars around the Postcolonial Atlantic. New York: New York University Press, 2012a.

. "Whence and Whither Postcolonial Theory?" New Literary History, v. 43, n. 2, p. 371-390, 2012 b.

VELOSO, Caetano. "Cinema novo". In: VELOSO, Caetano; GIL, Gilberto. Tropicália 2. WEA, 1993. LP.

1997a.

"Manhatã". Livro. Universal, 1997b. CD.

"Língua". Noites do Norte. Universal, 2001. CD.

YOUNG, Robert. "Postcolonial Remains." New Literary History, v. 43, n. 1, p. 19-42, 2012.

Utrecht, junho de 2012.

Tradução de Maria Isabel de Castro Lima Revisão de Claudia de Lima Costa 